\title{
Questionando os MÉtodos na PESQUiSA E NA PRÁTICA INTERDISCIPLINARES DA PSICOLOGIA AMBIENTAL
}

\author{
David Uzzell ${ }^{1}$ \\ Universidade de Surrey
}

\begin{abstract}
Este artigo apresenta a interdisciplinaridade como uma condição da Psicologia Ambiental dentro de uma abordagem holística e de uma pesquisa aplicada bem sucedida. Enfoca quatro questões referentes à condução da pesquisa interdisciplinar e à interação entre a pesquisa interdisciplinar ambiente-comportamento e as metodologias: não há métodos sem teoria; métodos no diálogo interdisciplinar: como comunicação, como relação política, para melhorar a compreensão; compartilhar métodos não deveria ser uma transação unilateral; a pesquisa interdisciplinar em um contexto ético.
\end{abstract}

Descritores: Psicologia ambiental. Pesquisa interdisciplinar. Ética.

To capítulo introdutório de um dos principais livros sobre Psicologia 1 Ambiental (Bell, Greene, Fisher, \& Baum, 2001, p. 10), os autores identificaram dois aspectos distintivos da Psicologia Ambiental: enfocar relações ambiente-comportamento como unidades totais e fazê-lo mais aplicadamente do que em outras áreas da Psicologia. Bell et al. poderiam também ter identificado uma terceira característica da pesquisa em Psicologia

1 Professor do Departamento de Psicologia e do Programa de Pós-Graduação em Psicologia Ambiental e membro do Grupo de Pesquisa em Psicologia Ambiental da Universidade de Surrey (Reino Unido); presidente da IAPS; coordenador de Environmental Psychology no Reino Unido; editor europeu do Journal of Architectural and Planning Research. Endereço eletrônico: d.uzzell@surrey.ac.uk 
Ambiental: a sua interdisciplinaridade. De fato, ser interdisciplinar é quase uma pré-condição para o preenchimento e para o sucesso de uma abordagem holística e para uma pesquisa aplicada bem sucedida. Embora a pesquisa interdisciplinar seja atraente precisamente porque é freqüentemente aplicada e holística, não o é sem perigos e armadilhas. É igualmente importante que compreendamos o que significa uma abordagem holística teorica e metodologicamente e no seu contexto interdisciplinar.

\section{Uma abordagem holística na pesquisa ambiente-comportamento: o que isto significa?}

Em um artigo recente escrito com Ombretta Romice, começamos por argüir que "Um dos desafios dos psicólogos ambientais é proporcionar registros holísticos do ambiente. Um dos desafios dos arquitetos é projetar ambientes que respondam à cadeia complexa de questões interligadas entre si; uma abordagem holística a um conjunto não-linear de condições". Nossa análise e compreensão das relações ambiente-comportamento podem estar situadas no ambiente ou na pessoa mas, como psicólogos ambientais $e$ projetistas, sabemos que as análises que não lidarem com as relações pessoaambiente, de um modo simbiótico e mutuamente reforçador, somente capturarão parte da história. Isto recorda os seis homens hindustani: "Havia seis homens hindustani, todos eles com uma mentalidade filosófica, que foram ver o Elefante, mas todos eles eram cegos".

Como Heat comenta a respeito dos homens hindustani: "Eles apreenderam, literalmente, vários aspectos do elefante, suas pernas, seu tronco, seu rabo e assim por diante, e então concluíam sobre o que o elefante 'realmente' era. Suas investigações revelaram muitas coisas sobre o elefante, mas a 'elefantidade' lhes escapava”' (Heat, 1974, p. 182).

Como pesquisadores ambiente-comportamento, tanto quanto como profissionais, aspiramos capturar a qualidade da "elefantidade", ie., uma apreciação holística do ambiente onde a análise está situada em ambos, na pessoa e no ambiente. Não é possível compreender o uso do ambiente fora 
da agência humana e, igualmente, não é possível apreciar completamente as percepções, atitudes e ações, tanto dos indivíduos quanto dos grupos, divorciado de um contexto sócio-ambiental. Tal análise não é nova: esta abordagem holística - do indivíduo, de seu mundo social e do ambiente - pode ser traçada desde o conceito de espaço de vida de Kurt Lewin (1951), ou mesmo antes, desde o conceito de "Umwelt" (1910) de Von Uexküll. O interesse atual dos psicólogos ambientais por questões de sustentabilidade é um bom exemplo de uma questão onde tal síntese é essencial.

Stokols (1995) questiona por uma abordagem mais inclusiva e integrada na Psicologia Ambiental. Isto poderia ser visto como uma outra perspectiva do holismo, podendo ser compreendida de várias maneiras. A interpretação de Stokols se refere a uma integridade interna à Psicologia Ambiental. Tal abordagem indica que deveríamos tentar construir modelos e teorias integradoras que proporcionassem uma explicação holística de processos fundamentais, como o processamento de informação ou de respostas emocionais a alguma dimensão ambiental.

Infelizmente, a geração de teorias integradas e inclusivas em psicologia não tem sido geralmente bem sucedida. De um modo alternativo, e em um nível meta-teórico, há a questão de especificar a relação entre o organismo individual e o seu mundo social. Isto significa reconciliar o pensamento intra-individual e a ação inter-individual, ou coordenar o que Doise (1976) referiu como o isomorfismo entre a lógica individual e a social. Um exemplo do que isto pode significar em termos de pesquisa pode ser vista em uma investigação sobre o papel e a influência da interação social no processo de aprendizagem (Blud, 1990; Uzzell \& Blud, 1993).

O restante deste artigo enfoca quatro questões referentes à condução da pesquisa interdisciplinar e à interação entre a pesquisa interdisciplinar ambiente-comportamento e as metodologias empregadas para realizar tal pesquisa:

- não há métodos sem teoria;

- o papel que os métodos representam em um diálogo interdisciplinar; 
- compartilhar métodos não deveria ser uma transação unilateral;

- a pesquisa interdisciplinar em um contexto ético.

\section{Não há métodos sem teoria}

Embora se dispense muita atenção aos métodos em pesquisa interdisciplinar - de fato, os métodos podem ser uma ponte entre disciplinas - é difícil haver uma discussão sobre metodologia sem se discutir a questão que estamos tentando responder. Todos os métodos têm neles encravados um "modelo de homem" ou um conjunto de suposições quanto às relações entre as pessoas e entre as pessoas e o seu ambiente físico. É claro que se pode conversar sobre metodologias a ser empregadas na pesquisa interdisciplinar, mas precisamos ter certeza de que o modelo de homem assumido (mas não necessariamente articulado) por aqueles que trabalham em uma disciplina (por ex., arquitetura) é o mesmo modelo de homem assumido por aqueles que trabalham em outra disciplina e com quem estão colaborando (por ex., psicologia). Em termos práticos, isto significa que os arquitetos podem estar trabalhando com um conjunto de suposições inerentemente comportamentalistas, enquanto os psicólogos podem estar trabalhando dentro de um modelo de papel ou relacional. Por exemplo, sabe-se que alguns arquitetos acreditam que o ambiente construído modela diretamente o comportamento humano e, por extensão, pode-se projetar o ambiente de modo a realizar metas sociais particulares (Lee, 1976).

Joachim Israel propôs que, em Psicologia Social, três modelos de homem foram prevalentes: o comportamentalista, o de papel e o relacional (Israel, 1972). As teorias comportamentalistas são orientadas primariamente para o indivíduo, que invariavelmente está no modo passivo. Por exemplo, a teoria de aprendizagem social explica os processos pelos quais um indivíduo adquire atitudes e comportamentos através de meios individualistas, freqüentemente em situações diádicas. Na teoria da troca, a ênfase está sobre as recompensas, os custos, os resultados e os níveis de comparação dos indivíduos envolvidos na troca, mais do que na díade como um sistema social. As 
teorias cognitivistas também estão bastante orientadas para o indivíduo, com um pequeno reconhecimento do contexto social no qual o indivíduo opera. Embora a posição cognitivista sugira que o indivíduo é autônomo, a ênfase no indivíduo ocasiona o fracasso em reconhecer o papel e a influência do grupo social e do pensamento e ação coletivos. As teorias comportamentalistas sugerem que, controlando o ambiente, é possível controlar o indivíduo. Se pudermos compreender o efeito dos eventos comportamentais sobre o comportamento das pessoas, pode ser possível antecipar a sua influência, e mesmo planejar aquela influência e controlar os eventos.

O segundo modelo de homem dominante na psicologia social, proposto por Israel, é o modelo do papel. A teoria do papel foi descrita como segue:

O homem tem certas posições no sistema social e, relacionadas a essas posições, há expectativas normativas referentes ao comportamento do indivíduo e concernentes a atributos relevantes. As posições independem de um ocupante específico. $\mathrm{O}$ mesmo é verdade quanto às expectativas dirigidas a uma posição; elas são definidas como o papel do titular de uma posição. (Israel, 1972, p. 140)

Diferentemente da teoria comportamentalista/cognivista, a teoria do papel supõe que o indivíduo vai se submeter passivamente à influência de construções sociais e políticas. Mesmo tendo uma forte orientação social, tende a minimizar as próprias percepções do indivíduo, suas normas e interesses. Embora permita que o indivíduo quebre regras e desempenhe outros papéis, sempre há uma sugestão de que as pessoas estão presas aos papéis.

O terceiro modelo de Israel é o modelo relacional, que está representado pelo trabalho de George Herbert Mead e pelos interacionistas simbólicos. Isto se espelha no registro de Moscovici sobre a psicologia sistemática. Mead escreveu: "um self pode surgir somente onde há um processo social dentro do qual este self tem a sua iniciação. Ele surge dentro daquele processo" (Mead, 1956, p. 42). Dentro deste modelo, Stringer escreve:

O homem não é visto como um feixe de traços, ou como um indivíduo que simplesmente responde a recompensas e punições, mas por suas relações sociais. $\mathrm{O}$ homem é a soma de suas interações sociais; por meio de interações constantes com outros, o self está constantemente mudando; a interação é plenamente recíproca 
pois não é dada prioridade nem aos processos individuais nem aos sociais. (Stringer. 1982, p58)

A abordagem relacional reconhece que toda ação ocorre em um ambiente social. Embora as ações pareçam ser ações individuais, em vários níveis, elas inevitavelmente implicam em outros membros do grupo ou da sociedade. Diversamente tanto do modelo comportamentalista quanto do de papel, poder-se-ia sustentar que o homem relacional tem um papel ativo em seu desenvolvimento e em sua relação com o restante da sociedade.

Retornando ao dito anteriormente, em um ambiente de trabalho interdisciplinar, enquanto ambos os grupos podem estar empregando metodologias similares, a análise dos resultados gerados por estas metodologias pode ser muito diferente como consequiência do quadro dos "modelos de homem" nos quais estas metodologias estão imbricadas.

Há ainda um outro modo pelo qual os métodos de pesquisa interagem com a teoria. Marsh, Rosser e Harré (1978), em seu livro Rules of Disorder, encorajaram os torcedores de futebol não apenas a expressar seus pensame ntos e sentimentos sobre o seu comportamento violento mas também a teorizar sobre o porquê deles se engajarem em atos de vandalismo e violência. Marsh argumenta que as pessoas comuns constroem teorias todo o tempo para responder por seu comportamento e, como cientistas sociais, nós deveríamos estar acessando estas teorias. Em outro contexto, suponho que elas poderiam ser chamadas de teorias indígenas. Isto tem uma ressonância com a noção de George Kelly do "homem, o cientista", na teoria do construto pessoal - personal construct theory - uma teoria que foi muito popular nos anos iniciais da Psicologia Ambiental (Bannister \& Fransella, 1971).

\section{O papel que os métodos desempenham no diálogo interdisciplinar}

Os métodos de pesquisa podem representar certos papéis no trabalho interdisciplinar. Os métodos de pesquisa podem ser usados: como um dispo- 
sitivo para a comunicação, como uma relação política e como um meio para melhorar a compreensão.

\section{Métodos como comunicação}

Toda vez que discutimos a colaboração interdisciplinar, um dos primeiros obstáculos a ser mencionado é o problema da comunicação; temos de encontrar meios mais efetivos de comunicar-nos - e por isso queremos geralmente dizer mais persuasivos - com os de outras disciplinas. As metodologias poderiam proporcionar uma tal linguagem para comunicar-nos um com o outro. Elas podem atuar como uma ponte entre duas disciplinas. Cada disciplina tem o seu próprio jargão especializado de termos e significados. Os métodos podem proporcionar um terreno de encontro - um território neutro no qual a Arquitetura e a Psicologia Ambiental, por exemplo, possam caminhar e tentar compreender o seu terreno compartilhado.

Igualmente, as metodologias podem servir para excluir o outro grupo. Elas também podem ser uma linguagem secreta que serve para colocar a experiência humana um, ou mesmo dois, degraus do que o grupo excluído pode reconhecer. Muitos argumentariam que a estatística serve a esta função na medida em que reduz a experiência humana a um conjunto de números que são infinitamente manipuláveis mas divorciados de tudo aquilo que aqueles que contribuíram para a estatística reconheceriam como si próprios.

\section{Métodos como relação política}

A posição do pesquisador é essencialmente política porque as técnicas que ele/ela usa afetarão as relações que ele tem com a comunidade (Uzzell, 1979). É igualmente política porque as relações que ele/ela forma no decorrer de sua pesquisa suscita questões de poder, influência, controle, responsabilidade, consideração e mesmo "de interesse público". De fato, o termo 'sujeito' empregado pelos psicólogos implica que a relação entre pesquisador e pesquisado é autoritária na medida em que as metas e os métodos da pesquisa são definidos quase totalmente pelo pesquisador, o sujeito é visto 
como capaz de oferecer pouco ou nada ao projeto da pesquisa porque o pesquisador é visto como um técnico capacitado, e que conhece mais, para coletar as informações; espera-se que o sujeito se conforme com as metas do pesquisador e obedeça quaisquer diretrizes dadas; o sujeito é encarado como um informante passivo, sem se considerar o que foi realizado pelo respondente, ou que vantagens podem advir à comunidade como um resultado do estudo.

O pesquisador também tem uma certa responsabilidade pelo bemestar público, assegurando que as técnicas de pesquisa que serão utilizadas não são estressantes e não colocam o indivíduo ou a comunidade em desvantagem. O pesquisador deveria igualmente ser responsável por aqueles que ele ou ela está estudando, mostrar que o que ele/ela está fazendo vale a pena. Finalmente, a pesquisa com comunidades freqüentemente tem implicações para a política pública, e isto terá implicações políticas em um sentido mais convencional.

Há um reconhecimento crescente que a relação do pesquisador com a comunidade requer uma ação responsável. Por esta razão, quando os estudantes do departamento de Arquitetura na Universidade de Strathclyde realizam uma pesquisa social na comunidade, pede-se que assinem uma Carta de Conduta que inclui: não levantar expectativas, expressar idéias claramente e sem nenhum jargão, informar, valorizar a opinião do outro, ser construtivo, entusiasta, preparado para chegar a um meio termo, ser auto-crítico, educado e respeitoso (Romice, 2002).

\section{Métodos para melhorar a compreensão}

Este é, evidentemente, o papel mais convencional dos métodos de pesquisa, porém recessitamos colocar a questão: compreensão de quem, e para quem? Isto dependerá do contexto no qual o psicólogo ambiental está trabalhando. Se nós tomarmos a exclusão social como um exemplo, se o psicólogo ambiental estiver realizando uma pesquisa interdisciplinar no contexto acadêmico, o foco pode bem ser nas saídas, i.e., em um aumento na compreensão dos processos sociais e psicológicos que levam à exclusão 
social. Se, de outro lado, o psicólogo ambiental estiver realizando uma pesquisa interdisciplinar com planejadores e arquitetos em um contexto de consultoria ou profissional, o foco desejado pode bem ser em resultados, i.e., em estratégias que levem à redução da exclusão social.

Foi sugerido haver uma lacuna quanto à aplicabilidade entre a Psicologia Ambiental e as profissões do design (Uzzell, 2000). Isto ocorreria porque os psicólogos ambientais e outros pesquisadores ambientecomportamento são capazes apenas de propor princípios gerais em resposta a necessidades específicas práticas. Se há uma lacuna, seria por causa de uma falha na comunicação, como os autores sugerem, ou seria porque os psicólogos não deram o tipo de respostas que profissionais, tais como arquitetos ou designers, requerem? Será esta lacuna de aplicabilidade devida ao fato que tanto os psicólogos ambientais quanto os arquitetos e planejadores falharam em entender ou apreciar a diferença entre saídas e resultados e, em consequiência, os psicólogos não forneneceram o tipo de respostas que os arquitetos e os designers estavam esperando ou queriam? Na minha experiência de trabalho como um consultor com outros grupos profissionais, esses grupos/empregados freqüentemente não conhecem, em verdade, como usar efetivamente os psicólogos ambientais. Tudo o que eles sabem é que o psicólogo ambiental deveria ser capaz de contribuir com algo de valor para aquilo que eles estão fazendo: "Empreguemos um psicólogo - ele pode lidar com o lado pessoal das coisas".

\section{Compartilhar métodos não deveria ser uma transação unilateral}

Estive discutindo a contribuição da Psicologia Ambiental para outras disciplinas, como a Arquitetura. Mas, qual é a contribuição de outras disciplina para a Psicologia Ambiental, especialmente em termos de metodologias? Quão recíproca é a relação? E, de novo, várias questões emergem aqui. Minha experiência é que outros grupos profissionais acham que os métodos empregados pelos psicólogos ambientais podem ser muito úteis - questioná- 
rios, entrevistas, mapas cognitivos e seus variantes, grupos focais, tarefas de escolha múltipla, mapeamento comportamental etc.

Qual tem sido o fluxo de metodologias de outras disciplinas para a Psicologia Ambiental? Provavelmente, a mais sofisticada é a análise de sintaxe espacial, que pode ser usada como um tipo de medida comportamental. A mais notável, contudo, é aquela de Lynch e a imagem da cidade, mas que é realmente um procedimento classificatório - a metodologia era antes casual e simplesmente envolvia acompanhar as pessoas enquanto elas percorriam as ruas de Boston, pedindo-lhes que dissessem o que as impressionava.

Quais métodos podem os arquitetos, planejadores e designers urbanos, por exemplo, proporcionar para que os psicólogos ambientais respondam às críticas de que deveria ter mais ambiente e mais análise ambiental na Psicologia Ambiental?

Ian Bentley e outros, em seu livro sobre Responsive Environments (Bentley, Alcock, Murrian, McGlynn, \& Smith, 1991) apontam que o design de um lugar afeta as escolhas que as pessoas fazem:

- Onde eles vão e onde não podem ir - permeabilidade - espaços públicos e privados

- A extensão de usos possíveis - variedade

- Quão facilmente as pessoas podem compreender quais oportunidade ou affordances ele proporciona - legibilidade

- O grau em que as pessoas podem usar o lugar para propósitos diferentes - robustez

- A aparência detalhada do lugar possibilita às pessoas fazer escolhas possíveis? - apropriação visual

- Afeta a escolha de experiências sensoriais das pessoas - riqueza

- Afeta o grau no qual as pessoas podem colocar a sua marca no lugar - personalização

Seria benéfico para nós, como psicólogos ambientais, especialmente se quisermos colocar o ambiente de volta na Psicologia Ambiental como alguns têm apontado, desenvolver metodologias que incorporem conceitos 
ambientais e espaciais como esses. Algumas dessas idéias já têm uma metodologia psicológica correlacionada ou, pelo menos, pode ser medida por psicólogos ambientais. Por exemplo, a permeabilidade poderia ser medida por meio da análise de sintaxe espacial; uma abordagem da variedade e legibilidade poderia ser por meio do conceito de affordances; a personalização pode ser traduzida em questões de identidade e de apego.

\section{A pesquisa interdisciplinar em um contexto ético}

A questão final a ser levantada é uma questão que raramente recebe atenção na Psicologia Ambiental, seja sozinha ou em psicólogos ambientais trabalhando no contexto de colaboração interdisciplinar. Cada disciplina desenvolve os seus próprios padrões éticos. Padrões éticos são importantes na medida em que produzem um quadro normativo para os cursos profissionais de ação e de regras de conduta. Os padrões éticos de cada profissão são desenvolvidos por muitos anos à luz da experiência prática. $\mathrm{O}$ emprego de métodos de pesquisa, em geral, e de metodologias específicas, em particular, muitas vezes tem implicações e obrigações éticas. Muito pouco, senão renhuma atenção, foi dada àquelas situações onde uma metodologia de uma disciplina é empregada por outra. Quando um método de pesquisa, mesmo um tão onipresente e genérico como a entrevista, é usado por aqueles a quem não foi ensinada tal habilidade como parte de seu próprio repertório disciplinar, é fácil para aqueles que emprestam a técnica de tratá-la de modo mecânico e ignorar os requerimentos éticos que acompanham o seu uso. Um estudo de caso recente, envolvendo dois grupos de estudantes de Arquitetura e de Psicologia Ambiental, proporciona um bom exemplo. Em um trabalho de campo conjunto, o modo como os dois grupos perceberam o público, pessoas e espaço, foi bastante diferente. Enquanto andando pelas áreas residenciais, os arquitetos desejavam entrar nas casas das pessoas, chamavam pelos moradores, perguntavam questões triviais e tentavam ser convidados para as moradias de modo a ver o seu arranjo interno e a organização do espaço. Os psicólogos estavam muito menos desejosos de se envolver nestes 
tipos de comportamentos. Os estudantes de Psicologia Ambiental, tendo sido educados nos moldes da profissão de psicologia e na ética da pesquisa, colocavam uma maior importância na privacidade dos moradores. Sentiam que eles tinham um "direito" de não serem perturbados; a idéia de chamar aos berros um morador vários andares acima violava a maior parte dos princípios de anonimato dos participantes. Para os estudantes de psicologia, tudo o que vinha da coleta de dados automaticamente colocava-os em uma relação pesquisador/ entrevistado. Pode ter ocorrido que os estudantes de Arquitetura não se viam em uma relação profissional com os moradores; os arquitetos justificavam o seu comportamento em termos de serem perguntas casuais que os moradores poderiam ter declinado responder. A presença de um grande número de estudantes pesquisadores no conjunto residencial pode igualmente ter levado os moradores a se sentir pressionados a responder, ou a se sentir desconfortáveis em suas casas e cercanias, o que de novo bvanta questões éticas de como tratamos pessoas que podem nem ter sido convidadas nem terem consentido em participar do estudo. Os estudantes de Arquitetura simplesmente não sentiam a mesma responsabilidade que os estudantes de Psicologia Ambiental sentiam quanto a uma ética de cuidado para com o público. Isto não é uma crítica, mas serve para ilustrar bastante graficamente como a adoção de metodologias em um contexto interdisciplinar também requer a adoção de padrões éticos supostos acompanhar o seu emprego.

\section{Conclusão}

A Psicologia Ambiental deve ser uma das áreas mais fascinantes de pesquisa psicológica justamente porque requer uma abordagem holística, é aplicada e permite que os pesquisadores ambiente-comportamento trabalhem com uma grande variedade de outras disciplinas. Isto não ocorre sem problemas. Alguns desses problemas foram articulados através dos anos e possivelmente levaram a uma diminuição na colaboração por causa das dificuldades por eles colocadas. Apesar dessas dificuldades, é claramente im- 
portante, e mesmo imperativo, que os psicólogos ambientais trabalhem em colaboração com outras disciplinas, como a Arquitetura. Somente deste modo asseguraremos que a nossa pesquisa e prática sejam válidas e relevantes. Porém, isto não pode ser realizado, como os seis homens hindustani o fizeram, cegamente.

Uzzell, D. (2005). Questioning methods in the interdisciplinary research and practice of environmental psychology. Psicologia USP, 16(1/2), 185-199.

\begin{abstract}
This article presents interdisciplinarity as a condition for Environmental Psychology, in a holistic approach and aiming at successful applied research. It discusses four questions referring to the conduction of interdisciplinary research and to the interaction between environmentbehavior interdisciplinary research and methodologies: there are no methods without theory; methods in interdisciplinary dialogue: as communication, as political relation, to improve understanding; sharing methods should not be a unilateral transaction; and finally, interdisciplinary research in an ethical context.
\end{abstract}

Index terms: Environmental psychology. Interdisciplinary research. Ethics.

Uzzell, D. (2005). Discussion sur des méthodes dans la recherche et dans la pratique interdisciplinaire de la psychologie environnementale. Psicologia USP, 16(1/2), 185-199.

Résumé: Cet article présente l'interdisciplinarité en tant que condition de la Psychologie Environnementale, dans une optique d'holisme et pour une recherche appliquée efficace. Il met en discussion quatre questions concernant la conduction de la recherche interdisciplinaire et l'interaction entre la recherche interdisciplinaire environnement-comportement et les méthodologies, à savoir: a) il n'y a pas de méthodes sans théorie; b) des méthodes dans le dialogue interdisciplinaire: telles que communication, relation politique, pour améliorer la compréhension; c) la répartition de 


\section{David Uzzell}

méthodes ne devrait pas être une transaction unilatérale; et, finalement, d) la recherche interdisciplinaire dans un contexte éthique.

Mots-clés: Psychologie de l'environnement. Recherche interdisciplinaire. Ethique.

\section{Referências}

Bannister, D., \& Fransella, F. (1971). Inquiring man: The theory of personal constructs. Harmondsworth, UK: Penguin.

Bell, P. A., Greene, T. C., Fisher, J. D, \& Baum, A. (2001). Environmental psychology. Fort Worth, Texas: Harcourt College.

Bentley I., Alcock A., Murrian P., McGlynn S., \& Smith G. (1991). Responsive environments. A manual for designers. London: Architectural Press.

Blud, L. M. (1990). Sons and daughters; observations on the way families interact during a museum visit. Museum Management and Curatorship, 9(3), 257-264.

Doise, W. (1976). Groups and individuals. Cambridge: Cambridge University Press.

Heat, T. (1974). Should we tell children about aesthetics, or should we let them find out in the street? In D. Canter \& T. Lee (Eds.), Psychology and the built environment (pp. 179-183). Tonbridge, Kent, UK: Whitefriars Press.

Israel, J. (1972). Stipulations and construction in the social sciences. In J. Israel \& H. Tajfel (Eds.), The context of social psychology: A critical assessment (pp. 123-211). London: Academic Press.

Lee, T. R. (1972, September). Psychology and architectural determinism (Part 3). The Architectural Journal, 22.

Lewin, K. (1951). Field theory in social science; selected theoretical papers (D. Cartwright, Ed.). New York: Harper \& Row.

Marsh, P., Rosser, E., \& Harre, R. (1978). The rules of disorder. London: Routledge.

Mead, G. (1956). The social psychology of GH Mead. Chicago: University of Chicago Press.

Romice, O (2002). A live project by the Community Design Unit \& Govanhill. http://hampden.arch.strath.ac.uk/govanhill/

Stokols, D. (1995). The paradox of environmental psychology. American Psychologist, 50, 821-837. 
Stringer, P. (1982). Towards a participatory psychology. In P. Stringer (Ed.), Confronting social issues (Vol. 2). London: Academic Press.

Uzzell, D. L. (1979). Four roles for the community researcher. Journal of Voluntary Action Research, 8(1-2), 66-76.

Uzzell, D. L. (2000). Environmental psychology and the environmental (design). Professions - a comment on Gärling and Hartig. Newsletter of the International Association of Applied Psychology, 12(1), 32-34.

Uzzell, D. L., \& Blud, L. M. (1993). Vikings! Children's social representations of history. In G. M. Breakwell \& D. Canter (Eds.), Empirical approaches to social representations (pp. 110-133). Oxford: Oxford University Press.

Uzzell, D. L., \& Romice, O. (2002). L'analyse des expériences environnementales. In G. Moser \& K. Weiss (Eds.), Vue sur l'environnement: exploration de la relation au cadre de vie (pp. 49-84). Paris: A. Colin.

Uzzell, D. L., \& Romice, O. (Forthcoming). Forty years on: A capital experience in psychology/architecture collaboration.

Uexküll, J. von. (1910). Die Umwelt. Die neue Rundschau, 21, 638-649.

Recebido em 5.04.2004

Revisto e encaminhado em 23.02.2005

Aceito em: 7.03.2005 